\title{
Peptide mediators of innate immunity in the small intestine
}

Antimicrobial peptides are components of a biochemical barrier against microbial colonisation. They occur in systems as evolutionarily distant as amoebae and human epithelia. These peptides are structurally diverse, ranging from linear, $\alpha$-helical molecules to dicyclic, $\beta$-sheet-containing peptides with three disulphide bonds [1]. Despite their varied primary and secondary structures, they are often amphipathic, a feature that allows the peptides to disrupt microbial cell membranes with subsequent killing, apparently by dissipation of electrochemical gradients [1].

The mammalian defensins consist of two wellcharacterised peptide families, the $\alpha$ - and $\beta$-defensins [2]. These peptides contain three disulphide bonds and have similar folded conformations even though their cysteine spacings and the pairings of their disulphide arrays differ [2]. The $\alpha$-defensins were discovered as antimicrobial peptides of phagocytic cell granules [3], but they are also found in human female reproductive tract epithelium $[4,5]$, in Leydig cells and Sertoli cells of mouse testis [6], and they are abundant in mouse and human Paneth cells [7]. The $\beta$-defensins have been described in bovine neutrophils and alveolar macrophages, airway, lingual, intestinal and colonic epithelium and in human kidney, skin, pancreas, salivary gland and urogenital epithelium [8].

Studies of human and rabbit neutrophil $\alpha$-defensin homologues reveal that such peptides may interact with microbial cell membranes by different mechanisms. When human neutrophil defensin HNP-2, a noncovalent dimer, inserts into model membranes, it forms large (c. $20 \AA$ ) multimeric pores [2]. In contrast, NP-1, a monomeric rabbit $\alpha$-defensin, renders such membranes permeable by creating large, transient defects in phospholipid bilayers [2,9]. The phospholipid composition of target cell membranes is an important determinant of peptide-membrane interaction and susceptibility to peptide killing [10].

In the gut of insects, frogs and mammals, specialised epithelial cells synthesise and release antimicrobial peptides to their apical surfaces, where, it is postulated, their role is to inhibit colonisation of the mucosa. Paneth cells are epithelial granulocytes that reside at the base of small intestinal crypts in most mammals. Their release of secretory granules contain- ing lysozyme [11], secretory phospholipase- $\mathrm{A}_{2}$ [12] and $\alpha$-defensins - termed cryptdins - suggests that they participate in mucosal barrier function. The appearance of enteric $\alpha$-defensin peptides coincides with Paneth cell differentiation, which occurs during the first trimester of human gestation and in the first 3 weeks of postnatal development in mice $[13,14]$.

Paneth cell $\alpha$-defensins show potent but selective activities in vitro against a number of microbes. For example, several bacterial species and the fungus Candida albicans are sensitive to recombinant HD-5, a human Paneth cell $\alpha$-defensin [15] and mouse cryptdins 1-6 are active against Listeria monocytogenes, Escherichia coli, Staphylococcus aureus and Salmonella enterica serotype Typhimurium $[16,17]$. Trophozoites of Giardia lamblia are killed by cryptdins 2 and 3 , but not by cryptdins 1 and 6 [18]. This differential killing activity suggests that the arginine at amino acid 15 in cryptdins 2 and 3 is important for anti-giardia activity, as the inactive cryptdin 1 and 6 peptides both contain glycine instead of arginine at residue 15 .

Precursors of $\alpha$-defensin are prepropeptides of $85-100$ amino acids that contain canonical signal peptides and acidic prosegments, with the defensin peptide processed from the C-terminal region of the initial translation product [19]. Interestingly, the prosegment of human neutrophil $\alpha$-defensin HNP-1 inhibits the antimicrobial activity of the peptide in in-vitro assays [20], but whether Paneth cell $\alpha$-defensin prosegments similarly inactivate their co-translated peptides is not known.

The mechanisms regulating defensin biosynthesis are not well understood. Physically, the human and mouse $\alpha$ - and $\beta$-defensin genes map to homologous positions on chromosome $8[21,22]$. The $\alpha$-defensin genes that are active in Paneth cells are structurally distinct from those expressed in the bone marrow: enteric $\alpha$ defensin genes contain only two exons rather than the three exons that characterise $\alpha$-defensin genes expressed by cells of myeloid origin [7]. In mouse testicular Sertoli cell cultures, cryptdin gene expression can be induced by co-culture with cells from the germ line and by administration of nerve growth factor [6]. The mouse cryptdin 4 gene, apparently 
silent in Paneth cells of the duodenum, is expressed at maximal levels in distal ileum [23]. Certain epithelial $\beta$-defensin genes in bovine trachea, colon and tongue are inducible by lipopolysaccharide, infection and wounding, but microbial antigens do not seem to be activators of $\alpha$-defensin genes in Paneth cells, as mouse cryptdin mRNA levels appear to be normal in germ-free mice and in aseptic fetal implants that differentiate subcutaneously. Functional analyses of Paneth cell defensin gene promoters have been hampered by a lack of expression systems for promoter-reporter transgenic constructs.

The objective of these comments has been to introduce Paneth cell $\alpha$-defensins as examples of endogenous peptides that potentially mediate mucosal immunity. It is now apparent that certain $\alpha$-defensins once considered to be Paneth cell specific may function in host defence at sites other than the small intestine. For example, as noted above, mouse cryptdins are present in testicular Sertoli cells and Leydig cells [6]. In women, Paneth cell $\alpha$-defensin transcripts are found in endocervix, endometrium and chorion [5], and the HD-5 peptide has been immunolocalised to endocervical epithelium of the female genito-urinary tract [24]. As studies of peptides with roles in epithelial barrier function progress, new antimicrobial peptides are likely to be discovered, and some may prove to be clinically useful.

I thank Drs Charles L. Bevins, Yashwant R. Mahida, Michael E. Selsted, and Carole L. Wilson for useful discussions. Supported by NIH grants DK44632, DK33506, and HD31852.

ANDRE J. OUELLETTE: Departments of Pathology and Microbiology and Molecular Genetics,

College of Medicine, University of California, Irvine, Irvine, CA 92697-4800, USA E-mail: aouellet@uci.edu

\section{References}

1. Boman HG. Peptide antibiotics and their role in innate immunity. Annu Rev Immunol 1995; 13: 61-92.

2. White SH, Wimley WC, Selsted ME. Structure, function, and membrane integration of defensins. Curr Opin Struct Biol 1995; 5: $521-527$.

3. Lehrer RI, Ganz T, Selsted ME. Defensins: endogenous antibiotic peptides of animal cells. Cell 1991; 64: 229-230.

4. Ganz T, Weiss J. Antimicrobial peptides of phagocytes and epithelia. Semin Hematol 1997; 34: 343-354.
5. Svinarich DM, Wolf NA, Gomez R, Gonik B, Romero R. Detection of human defensin 5 in reproductive tissues. $A m J$ Obstet Gynecol 1997; 176: 470-475.

6. Grandjean V, Vincent S, Martin L, Rassoulzadegan M, Cuzin F. Antimicrobial protection of the mouse testis: synthesis of defensins of the cryptdin family. Biol Reprod 1997; 57: 11151122 .

7. Ouellette AJ, Selsted ME. Paneth cell defensins: endogenous peptide components of intestinal host defense. FASEB $J 1996$; 10: $1280-1289$.

8. Ganz T, Lehrer RI. Antimicrobial peptides of vertebrates. Curr Opin Immunol 1998; 10: 41-44.

9. Hristova K, Selsted ME, White SH. Interactions of monomeric rabbit neutrophil defensins with bilayers: comparison with dimeric human defensin HNP-2. Biochemistry 1996; 35: 11888-11894.

10. Hristova K, Selsted ME, White SH. Critical role of lipid composition in membrane permeabilization by rabbit neutrophil defensins. J Biol Chem 1997; 272: 24224-24233.

11. Geyer G. Lysozyme in Paneth cell secretions. Acta Histochem 1973; 45: 126-132.

12. Mulherkar R, Rao RS, Wagle AS, Patki V, Deo MG. Enhancing factor, a Paneth cell specific protein from mouse small intestines: predicted amino acid sequence from RT-PCR amplified cDNA and its expression. Biochem Biophys Res Commun 1993; 195: 1254-1263.

13. Mallow EB, Harris A, Salzman N it al. Human enteric defensins - gene structure and developmental expression. $J$ Biol Chem 1996; 271: 4038-4045.

14. Bry L, Falk P, Huttner K, Ouellette A, Midtvedt T, Gorden JI. Paneth cell differentiation in the developing intestine of normal and transgenic mice. Proc Natl Acad Sci USA 1994; 91: $10335-10339$.

15. Porter EM, van Dam E, Valore EV, Ganz T. Broad-spectrum antimicrobial activity of human intestinal defensin 5. Infect Immun 1997; 65: 2396-2401.

16. Eisenhauer PB, Harwig SSL, Lehrer RI. Cryptdins: antimicrobial defensins of the murine small intestine. Infect Immun 1992; 60: 3556-3565.

17. Ouellette AJ, Hsieh MM, Nosek MT et al. Mouse Paneth cell defensins: primary structures and antibacterial activities of numerous cryptdin isoforms. Infect Immun 1994; 62: 5040-5047.

18. Aley SB, Zimmerman M, Hetsko M, Selsted ME, Gillin FD. Killing of Giardia lamblia by cryptdins and cationic neutrophil peptides. Infect Immun 1994; 62: 5397--5403.

19. Ganz T, Lehrer RI. Defensins. Curr Opin Immunol 1994; 6: 584-589.

20. Valore EV, Martin E, Harwig SSL, Ganz T. Intramolecular inhibition of human defensin HNP-1 by its propiece. J Clin Invest 1996; 97: 1624-1629.

21. Bevins CL, Jones DE, Dutra A, Schaffzin J, Muenke M. Human enteric defensin genes: chromosomal map position and a model for possible evolutionary relationships. Genomics 1996; 31: 95-106.

22. Liu LD, Zhao CQ, Heng HHQ, Ganz T. The human $\beta$ defensin- 1 and $\alpha$-defensins are encoded by adjacent genes: two peptide families with differing disulficle topology share a common ancestry. Genomics 1997; 43: 316-320.

23. Darmoul D, Ouellette AJ. Positional specificity of defensin gene expression reveals Paneth cell heterogeneity in mouse small intestine. Am $J$ Physiol 1996; 271: G68-G74.

24. Quayle AJ, Porter EM, Nussbaum AA et al. Gene expression, immunolocalization, and secretion of human defensin-5 in human female reproductive tract. Am I Pathol 1998; 152: $1247-1258$ 